\title{
Thyroid cancer burden and economic impact on the Brazilian public health system
}

Carolina Castro Porto Silva Janovsky ${ }^{1,2}$, Marcio Sommer Bittencourt2,3, Maykon Anderson Pires de Novais ${ }^{4}$, Rui M. B. Maciel', Rosa Paula M. Biscolla', Paola Zucchi ${ }^{4}$

\begin{abstract}
Objective: Recent data indicates an increasing incidence of thyroid cancer not accompanied by a proportional increase in mortality, suggesting overdiagnosis, which may represent a big public health problem, particularly where resources are scarce. This article aims to describe and evaluate the procedures related to investigation of thyroid nodules and treatment and follow-up of thyroid cancer and the costs for the Brazilian public health system between 2008 and 2015. Materials and methods: Data on procedures related to investigation of thyroid nodules and treatment/follow-up of thyroid cancer between 2008 and 2015 in Brazil were collected from the Department of Informatics of the Brazilian Unified Health System (Datasus) website. Results: A statistically significant increase in the use of procedures related to thyroid nodules investigation and thyroid cancer treatment and follow-up was observed in Brazil, though a reduction was noted for procedures related to the treatment of more aggressive thyroid cancer, such as total thyroidectomy with neck dissection and higher radioiodine activities such as 200 and 250 milicuries $(\mathrm{mCi}$ ). The procedures related to thyroid nodules investigation costs increased by $91 \%$ for thyroid ultrasound ( $p=0.0003$ ) and $128 \%$ in thyroid nodule biopsy $(p<0.001)$. Costs related to treatment and follow-up related-procedures increased by $120 \%$. Conclusion: The increase in the incidence of thyroid cancer in Brazil is directly associated with an increased use of diagnostic tools for thyroid nodules, which leads to an upsurge in thyroid cancer treatment and followup-related procedures. These data suggest that substantial resources are being used for diagnosis, treatment and follow-up of a potentially indolent condition. Arch Endocrinol Metab. 2018;62(5):537-44
\end{abstract}

Keywords

Thyroid cancer; economic impact; Brazilian public health system; costs; overdiagnosis
${ }^{1}$ Centro de Doenças da Tireoide e Laboratório de Endocrinologia Molecular e Translacional, Divisão de Endocrinologia, Departamento de Medicina, Escola Paulista de Medicina, Universidade Federal de São Paulo (EPM-Unifesp), São Paulo, SP, Brasil ${ }^{2}$ Centro de Medicina Preventiva, Hospital Israelita Albert Einstein, São Paulo, SP, Brasil

${ }^{3}$ Núcleo de Pesquisa Clínica e Epidemiológica, Hospital das

Clínicas da Faculdade de Medicina da Universidade de São Paulo (HCFMUSP), São Paulo, SP, Brasil ${ }^{4}$ Divisão de Economia da Saúde, Departamento de Medicina, Escola Paulista de Medicina, Universidade Federal de São Paulo, São Paulo, SP, Brasil

Correspondence to: Rosa Paula Mello Biscolla Rua Pedro de Toledo, 669, $11^{\text {th }}$ floor 04039-032 - São Paulo, SP, Brasil rosapaula.biscolla@grupofleury.com.br

Received on Apr/4/2018 Accepted on Aug/2/2018

DOI: $10.20945 / 2359-3997000000074$

\section{INTRODUCTION}

$\mathrm{T}$ hyroid nodules are a very common condition, found by palpation in 4-7\% of the adult population and in more than $50 \%$ if an image exam is used (1-4). Despite the general knowledge that thyroid nodules are seldom malignant, about 5\%, some studies with necropsies have shown that thyroid cancer may be present in up to $36 \%$ of individuals who died from other causes not thyroid-related (5-9).

Indeed, thyroid cancer is the most common endocrine cancer, with an incidence rate of 7.57 per 100,000 women and 1.49 per 100,000 men in Brazil (10), though recent data indicate an increase in incidence worldwide (2,11-14). Interestingly, this increase is not accompanied by a proportional increase in mortality, suggesting the potential diagnosis of earlystage cancer associated with a lower risk of recurrence or the potential occurrence of overdiagnosis, which means diagnosing a disease that would never cause symptoms or death during a patient's expected life span (2,15-18).

This phenomenon has been documented in a recent South Korean study, which reported a dramatic rise in the diagnosis of thyroid cancer, reaching epidemic levels, due to the incorporation of a neck ultrasound as part of a routine screening check-up (11). In addition, data from the United States suggest that despite an overall increase in the incidence of thyroid cancers, this phenomenon was more prominent in regions with widely available health care access $(15,19,20)$. Interestingly, such findings seem to be occurring worldwide, leading to increased concern over its public health impact (20).

Recent Brazilian data from the population-based cancer registry (RCBP) has demonstrated a significant increase in the incidence of thyroid cancer in the city of São Paulo from 2008 to 2012 (21). Although this 
seems to occur throughout the country, the results are more impressive in the southern, southeastern and northeastern regions, where diagnostic tools are more widely available $(10,15,22-25)$.

Since overdiagnosis may represent an outsize problem for public health services, it is fundamental to evaluate this phenomenon especially in developing countries, where resources are scarce (22). However, no data on the quantity of procedures performed to investigate a thyroid nodule, treat and follow thyroid cancer patients, as well as its costs for the Brazilian public health system (SUS) are currently available. Therefore, the aim of this study is to describe and discuss the procedures related to investigation of thyroid nodules, treatment and follow-up of thyroid cancer and the direct costs for the Brazilian public health system between 2008 and 2015 .

\section{MATERIALS AND METHODS}

A retrospective study was performed using the Department of Informatics of the Unified Health System (Datasus) database (datasus.saude.gov.br) as the main source of information, accessed during the month of December 2016.

We considered all the procedures present in the algorithm proposed by the national endocrine society for the investigation and management of thyroid nodules (Figure 1 - supplementary material) (26). As thyroid-stimulating hormone TSH measurements are used to investigate thyroid disfunctions and there is not a specific Datasus code for TSH dosage requested for thyroid nodule evaluation, data about TSH measurements were not included.

The quantity and tariffs of the procedures between 2008 and 2015 were accessed through the TABNET link on the Datasus homepage. The data were organized according to the place where the procedure was performed, not by the patient's birthplace. We analyzed data from the entire country, stratified by the five Brazilian regions (south, southeast, northeast, north, and central-west). It was considered only the treatment related-procedures restricted to the 10th edition International Classification of disease code C-73 ('Thyroid Cancer") (27).

The tariffs were described in the Brazilian local currency, i.e. reais. Considering that the tariff (direct cost) of each procedure for our Public Health System, collected from the SIGTAP (sigtap.datasus.saude.gov. br), hasn't changed since 2008, there was no need for adjusting to the inflation rate.

The thyroid nodule investigation and treatment/ follow-up-related procedures analyzed, as well as each tariff are described in Tables 1 and 2.

Brazilian population estimates were obtained from the Brazilian Institute of Geography and Statistics (IBGE) website to adjust the quantity of procedures per 100,000 people in each region. The incidence and mortality rate of thyroid cancer was obtained from the latest version of the National Cancer Institute/ Population-based Cancer Registry (INCA/RCBP) database, using the tenth edition of the International Classification of Disease (ICD-10) code "C73" (27).

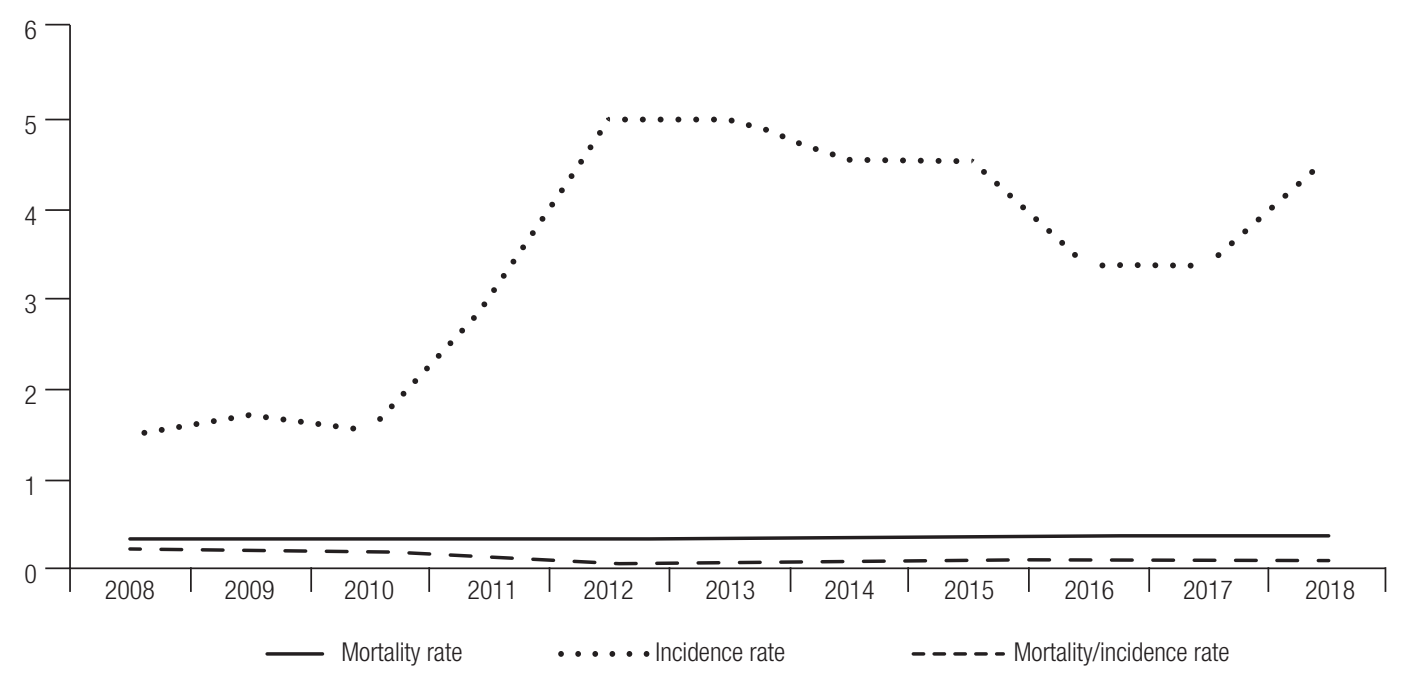

Figure 1. Incidence versus Mortality of Thyroid Cancer (ICD-10: C73) between 2008 and 2018 in Brazil (rate per 100,000 people). Source: Data obtained from the National Cancer Institute (INCA). 
The statistical analysis was performed with Stata 13.0 (28). To verify the trend of each variable during the period of the study, a Spearman correlation was used. The significance level adopted was $5 \%$.

Table 1. Thyroid Cancer Diagnosis-related Procedures Available at Datasus in December 2016 (sigtap.datasus.saude.gov.br)

\begin{tabular}{lcc}
\hline Procedure name & Datasus code & Tariff (R\$) \\
\hline Thyroid ultrasound & $02.05 .02 .012-7$ & 24.20 \\
Thyroid FNAB & $02.01 .01 .047-0$ & 23.73 \\
Thyroid scintigraphy & $02.08 .03 .002-6$ & 77.28 \\
Thyroid scintigraphy with suppression & $02.08 .03 .003-4$ & 107.30 \\
and/or stimulus* & \\
\hline
\end{tabular}

${ }^{*}$ Suppression with T3 or T4/stimulus with recombinant human TSH (thyroid-stimulating hormone). FNAB: fine-needle aspiration biopsy.

Table 2. Thyroid Cancer Treatment-related Procedures Available at Datasus in December 2016 (sigtap.datasus.saude.gov.br)

\begin{tabular}{lcc}
\hline Procedure name & Datasus code & Tariff (R\$) \\
\hline Oncologic total thyroidectomy & $04.16 .03 .027-0$ & 2836.30 \\
Total thyroidectomy with neck dissection & $04.02 .01 .005-1$ & 767.77 \\
$\begin{array}{l}\text { Total thyroidectomy with neck dissection } \\
\text { in oncology }\end{array}$ & $04.16 .03 .012-2^{\#}$ & 1606.86 \\
Trans sternal resection of thyroid cancer & $04.16 .03 .036-0$ & 4186.64 \\
Trans sternal resection of goiter in & $04.16 .03 .005-0^{*}$ & 2618.25 \\
oncology & & \\
RAl $30 \mathrm{mCi}$ & $03.04 .09 .005-0$ & 443.70 \\
RAl $50 \mathrm{mCi}$ & $03.04 .09 .006-9$ & 614.70 \\
RAl $100 \mathrm{mCi}$ & $03.04 .09 .002-6$ & 1071.90 \\
RAl $150 \mathrm{mCi}$ & $03.04 .09 .001-8$ & 1289.90 \\
RAl $200 \mathrm{mCi}$ & $03.04 .03 .003-4$ & 1471.32 \\
RAl $250 \mathrm{mCi}$ & $03.04 .09 .004-2$ & 1810.32 \\
& $03.03 .12 .001-0$ & \\
WBS & $02.08 .03 .004-2$ & 338.70 \\
Serum thyroglobulin & $02.02 .06 .036-5$ & 15.35 \\
\hline
\end{tabular}

\# Code 04.16.03.012-2 was revoked in January 2013. Afterwards, codes 04.16.02.018-6 (unilateral neck dissection in oncology) and 04.16.03.027-0 (total thyroidectomy in oncology) were used to describe this procedure.

* Code 04.16.03.005-0 was revoked in January 2013. Afterwards, code 04.16.03.036-0 (trans sternal resection of thyroid cancer) was used to describe this procedure.

RAl: radioiodine treatment; WBS: whole body scan.

\section{RESULTS}

In 2008, thyroid cancer incidence rate was 1.51 per 100,000 individuals, rising progressively to 4.57 per 100,000 individuals in $2018(\mathrm{p}=0.06)$. The mortality rate rose from 0.30 in 2008 to 0.36 in 2018 $(\mathrm{p}=0.004)$. However, comparing the mortality rate to the incidence rate (mortality rate/incidence rate) there was a negative trend $(\mathrm{p}=0.07$, rho -0.0674 , Figure 1$)$.

Contributing to this incidence's upsurge, it was observed a statistically significant increase in the number of thyroid nodule investigation tools (thyroid ultrasound and fine-needle aspiration biopsy FNAB), and treatment/follow-up-related procedures (oncologic total thyroidectomy and radioiodine treatment $100 \mathrm{mCi}$ and $150 \mathrm{mCi}$ ) between 2008 and 2015 in Brazil and in all geographic regions (Tables 3,4 and Figure 2). Data on the increase in treatmentrelated procedures per geographic region are described in the supplementary material.

The use of thyroid scintigraphy with or without stimulus and/or suppression has reduced during the analyzed period (Table 3 ).

However, the procedures related to more aggressive thyroid cancer treatment reduced significantly during the same period. For example, total thyroidectomy with neck dissection decreased from 0.21 per 100,000 people in 2008 to 0.12 per 100,000 people in 2015 $(\mathrm{p}=0.03)$, while the number of higher radioiodine activities, such as $200 \mathrm{mCi}$ and $250 \mathrm{mCi}$, both decreased from 0.33 and 0.32 per 100,000 people in 2008 , to 0.26 and 0.19 per 100,000 people in 2015 , respectively $(\mathrm{p}=0.0991$ and $\mathrm{p}<0.0001)$. The comparison among levels of radioiodine used for thyroid cancer ablation is shown in Figure 3.

Considering treatment for low-risk patients, an increase in the use of lower doses of RAI (30-50 mCi) for thyroid cancer treatment was noted, although this data is only available since 2014 .

Table 3. Number of Thyroid Cancer Diagnosis-related Procedures per 100,000 People, between 2008 and 2015 in the Brazilian Public Health System (SUS)

\begin{tabular}{lccccccccc}
\hline & $\mathbf{2 0 0 8}$ & $\mathbf{2 0 0 9}$ & $\mathbf{2 0 1 0}$ & $\mathbf{2 0 1 1}$ & $\mathbf{2 0 1 2}$ & $\mathbf{2 0 1 3}$ & $\mathbf{2 0 1 4}$ & $\mathbf{2 0 1 5}$ & $\mathbf{p}$ \\
\hline Thyroid ultrasound & 154.5 & 173.2 & 196.7 & 173.5 & 196.1 & 207.7 & 232.8 & 229.6 & $<0.001$ \\
Thyroid FNAB & 10.3 & 10.1 & 10.4 & 11.2 & 13.5 & 14.6 & 15.6 & 16.9 & $<0.001$ \\
Thyroid scintigraphy & 6.2 & 5.5 & 5.6 & 5.6 & 5.4 & 5.5 & 5.3 & 4.8 & 0.001 \\
Thyroid scintigraphy with suppression/stimulus* & 0.09 & 0.06 & 0.06 & 0.04 & 0.04 & 0.05 & 0.07 & 0.08 & 0.795 \\
\hline
\end{tabular}

* Suppression with T3 or T4/stimulus with recombinant human TSH (thyroid-stimulating hormone).

FNAB: fine-needle aspiration biopsy.

Source: datasus.saude.gov.br. 
Table 4. Number of Thyroid Cancer Treatment and Follow-up-related Procedures per 100,000 People, between 2008 and 2015 in the Brazilian Public Health System (SUS)

\begin{tabular}{|c|c|c|c|c|c|c|c|c|c|}
\hline & 2008 & 2009 & 2010 & 2011 & 2012 & 2013 & 2014 & 2015 & p \\
\hline Oncologic $\Pi$ & 0.8 & 0.9 & 1.0 & 1.1 & 1.2 & 1.7 & 1.8 & 1.9 & $<0.001$ \\
\hline TT with neck dissection & 0.2 & 0.2 & 0.2 & 0.2 & 0.2 & 0.2 & 0.2 & 0.1 & 0.027 \\
\hline TT with neck dissection in oncology & 0.48 & 0.56 & 0.65 & 0.73 & 0.84 & - & - & - & $<0.001$ \\
\hline Trans sternal resection of thyroid cancer* & 0.03 & 0.04 & 0.03 & 0.04 & 0.02 & 0.02 & 0.02 & 0.03 & 0.046 \\
\hline RAl $30 \mathrm{mCi}^{\star *}$ & - & - & - & - & - & - & 0.06 & 0.07 & $<0.001$ \\
\hline RAl $50 \mathrm{mCi}^{* *}$ & - & - & - & - & - & - & 0.04 & 0.07 & $<0.001$ \\
\hline RAl $100 \mathrm{mCi}$ & 0.4 & 0.5 & 0.7 & 0.7 & 0.8 & 0.9 & 0.9 & 0.9 & 0.027 \\
\hline RAl $150 \mathrm{mCi}$ & 0.4 & 0.5 & 0.7 & 0.7 & 0.8 & 0.9 & 0.8 & 0.8 & 0.055 \\
\hline RAl $200 \mathrm{mCi}$ & 0.3 & 0.3 & 0.3 & 0.3 & 0.3 & 0.3 & 0.3 & 0.3 & 0.127 \\
\hline RAI $250 \mathrm{mCi}$ & 0.3 & 0.3 & 0.3 & 0.2 & 0.2 & 0.2 & 0.2 & 0.2 & 0.007 \\
\hline WBS & 3.8 & 3.7 & 4.2 & 4.6 & 4.4 & 5.1 & 4.9 & 4.9 & 0.008 \\
\hline Serum thyroglobulin & 23.3 & 27.3 & 37.3 & 39.4 & 38.7 & 39.8 & 44.9 & 48.5 & $<0.001$ \\
\hline
\end{tabular}

* Data includes codes 04.16.03.005-0 (from 2008 to 2013) and 04.16.03.036-0 (from 2013 to 2016).

** Data available since 2014

RAl: radioiodine treatment; TT: total thyroidectomy; WBS: whole body scan.

Only the procedures restricted to the IDC: $\mathrm{C73}$ were considered.

Source: Data obtained from datasus.saude.gov.br
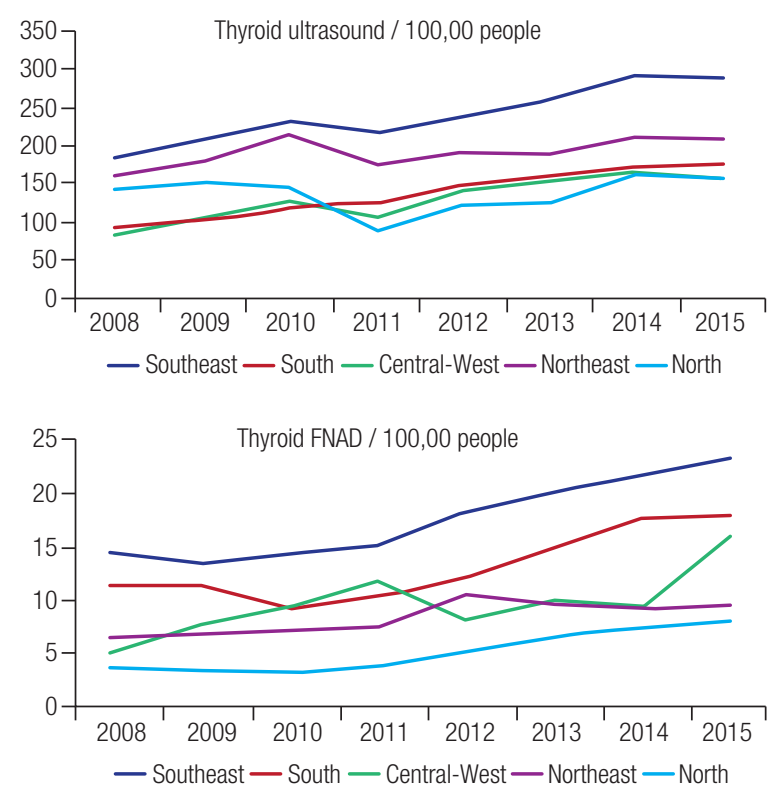

Figure 2. Increase in Numbers of Procedures Related to Thyroid Nodule Investigation between 2008 and 2015 in the Brazilian Public Health System (SUS) by Regions.

FNAB: fine-needle aspiration biopsy.

Regarding direct costs to the Brazilian public health system, a $84 \%$ increase in procedures related to thyroid nodule investigation costs was noted in this period. Thyroid ultrasound costs increased by $91 \%$ $(\mathrm{p}=0.0003)$, and thyroid nodule biopsy (fine-needle aspiration biopsy) costs increased by $128 \%(\mathrm{p}<0.001)$

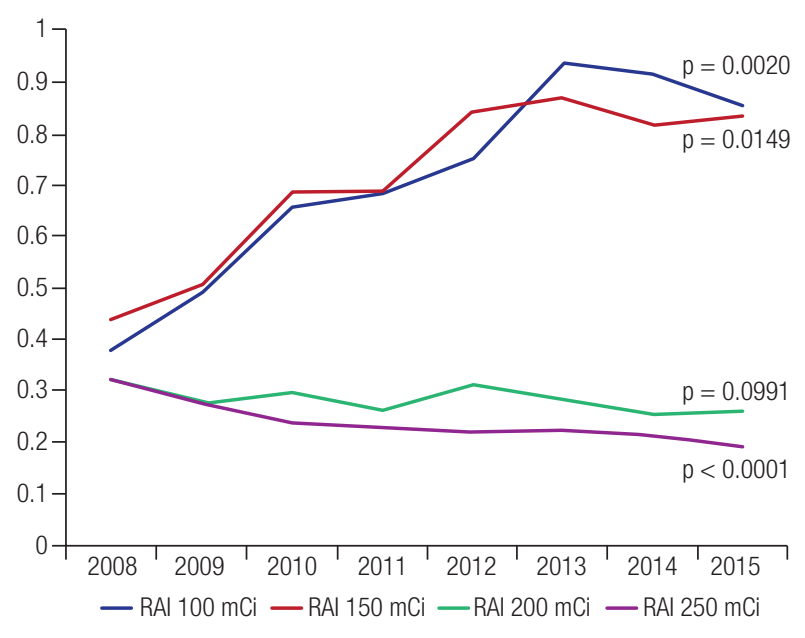

Figure 3. Radioactive lodine Use per 100,000 People During 2008-2015 in the Brazilian Public Health System (SUS).

RAl: radioiodine treatment.

from 2008 to 2015 (Figure 4A). Similarly, there was a $120 \%$ increase in the total costs of treatment-related procedures performed during the same period, mainly due to the increase in the use of oncologic total thyroidectomy, radioiodine activities of 100 and 150 $\mathrm{mCi}$ RAI and follow-up procedures (Figure 4B). These procedures (diagnostic and therapeutic) altogether represented an expense of almost 230 million reais for the unified health system (SUS) in this 8-year period. 

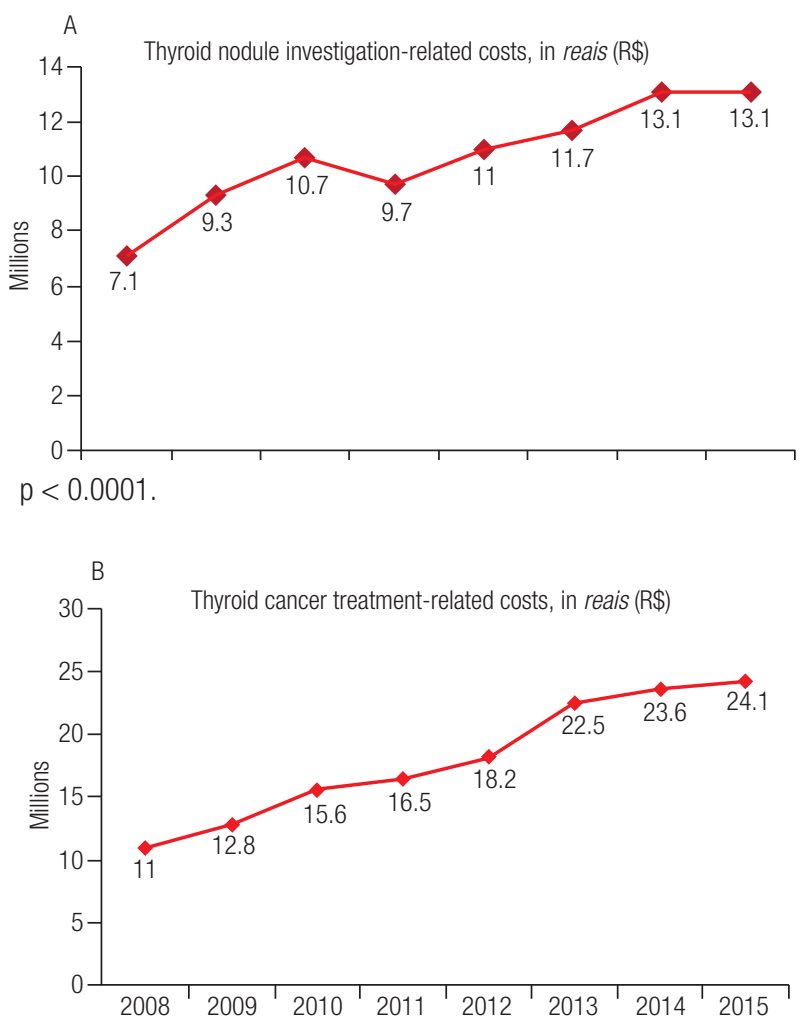
$p<0.001$.

Figure 4. Increase in Costs Related to Thyroid Cancer Diagnosis $(\mathbf{A})$ and Treatment (B) between 2008 and 2015 in the Brazilian Public Health System.

\section{DISCUSSION}

Our study demonstrates an important upsurge in the use of procedures related to thyroid nodule investigation and thyroid cancer treatment and follow-up in Brazil from 2008 to 2015. This overuse of resources has increased the costs of the disease for the Brazilian public health system.

Interestingly, this increase seems to be mostly driven by procedures related to early-stage cancer, as the use of more aggressive surgery and higher-dose radiation therapy has decreased over time. Although this trend might be interpreted as earlier diagnosis due to more intensive use of screening strategies, one would expect a reduction in mortality if this were true. Collectively, this evidence can be interpreted as a potential overdiagnosis of cases, which are unlikely to progress to overt or aggressive forms of cancer.

The clinical relevance of a nodule incidentally found by ultrasound is unclear because it probably will not prompt symptoms or neoplastic dissemination (29-31). Indeed, studies have shown that $19 \%$ to $68 \%$ of the population presents with a thyroid nodule on a neck ultrasound $(32,33)$. In these cases, an early thyroid cancer diagnosis would not improve prognosis, but it may increase the risks related to unnecessary aggressive treatment (31).

To avoid overdiagnosis and overuse of resources, health systems in different countries are reconsidering the usefulness of neck ultrasound to screen for thyroid cancer in asymptomatic individuals. In the United Kingdom, only a thyroid specialist is allowed to order neck ultrasounds for patients with thyroid nodules (34). Along the same lines, the American Preventive Service Task Force (USPSTF) recently released its guidelines, in which it strongly recommends against using neck ultrasounds for thyroid cancer screening in asymptomatic people (35). Restricting the use of neck ultrasounds to cases in which palpable nodules are detected by a specialist could be an option for reducing healthcare resource utilization in the Brazilian public health system.

Despite the increase in total thyroidectomies performed during the period of this study, a significant reduction in the use of more complex surgeries, such as total thyroidectomies with neck dissection, was noted. This finding suggests that smaller tumours are being resected, without lymph node metastasis and probably with no important clinical repercussion, which corroborates the hypothesis of overdiagnosis (36-38). This concept is reinforced by recent data showing a similar effect with watchful waiting compared with surgery when a thyroid nodule is diagnosed as cancer $(39,40)$.

Our results have also documented a significant increase in radioiodine treatment with 100 and 150 $\mathrm{mCi}$, the most common activities prescribed for thyroid cancer patients with intermediate or high risk of recurrence. Lately, national and international guidelines on thyroid cancer management have recommended against the use of radioiodine in low risk of recurrence cases $(26,41)$. Even so, Roman and cols. (42) observed that $30 \%$ of the patients with tumours $<1 \mathrm{~cm}$ still receive radioiodine activities despite recent guidelines against it (42). In our study, it is not clear if the rise observed in the use of RAI is associated with diagnosis of higher-risk tumours or if clinicians continue to prescribe RAI due to a lack of knowledge or for thyroid remnant ablation. In these cases, the use of RAI could facilitate the use of serum thyroglobulin measurements in the thyroid cancer follow-up (43). Nevertheless, the reduction in prescribing higher RAI activities (200 and 
$250 \mathrm{mCi}$ ) implies that less aggressive cases are being diagnosed.

There was a numerical increase in the use of low radioiodine activities $(30-50 \mathrm{mCi})$, despite the small absolute number of those procedures, as they were only included in the list of authorized procedures by the Brazilian Public Health System in 2014. Recent studies have shown that the benefits of lower RAI doses equal higher doses, such as $100 \mathrm{mCi}$ for low- to intermediaterisk patients, with fewer side effects and reduced costs $(44,45)$. This may be a tendency as low-risk cases are being dignosed. However, the low request for these procedures may indicate that low-risk patients have not received any RAI treatment, which is the most recent standard of care expected for low-risk cases $(46,47)$, or they have received $100 \mathrm{mCi}$ despite the recent literature recommendations (46-49).

The southeastern region of Brazil had the highest increase in number of procedures as well as expenditures related to thyroid cancer diagnosis and treatment. This may have occurred due to the choice of using the Datasus search filter of patients' treatment place and not their birthplace. It is known that the southeastern region is the richest region and has the largest cancer centres in Brazil, which are referred centres for people from other regions. So the expectation on overuse of resources is higher. Nonetheless, this important upsurge in diagnostic and treatment-related procedures seems to be spread throughout the country, irrespective of region.

From 2010 to 2015 , there was a $66 \%$ increase in costs related to cancer in Brazil, from 2.1 billion reais to 3.5 billion reais, according to the National Cancer Institute (INCA). During the 8-year study period, there was also a significant increase in the cost of thyroid nodule investigation and thyroid cancer treatment and follow-up in all Brazilian regions, proportionally higher than what was observed for other types of cancer $(106 \%$ for thyroid cancer vs $66 \%$ for all types of cancer). This excessive expenditure for a potentially indolent disease adds on to the hypothesis of overdiagnosis.

Our study, however, must be read within the context of its design. The completeness of the INCA/RCBP database is questionable in some regions. Therefore, the inputs on thyroid cancer incidence may be underestimated. Also, the Datasus database depends on the registry of the procedures performed in each hospital or healthcare service across the country, thus it does not warrant a completely reliable source of information.
Additionally, there are different codes to describe the same procedure, for example, "total thyroidectomy" versus "total thyroidectomy in oncology". This study considered only the code for total thyroidectomy in oncology, which excludes thyroid surgeries for benign diseases. However, the figures may be underestimated, as it is possible that the code for total thyroidectomy (not oncologic) also might have been used to describe surgeries for cancer. Another coding problem is that the code used to describe thyroid FNAB because it is used to describe thyroid as well as parathyroid FNAB. It is known that thyroid tumors are 16 times more common than parathyroid tumors (50). We therefore assumed all FNAB were related to thyroid cancer. Although this may result in a small overestimation of its use, there has been no change in the incidence of parathyroid tumors, and the documented increase over the last eight years is unlikely to have changed if the cases used for parathyroid disease were excluded. Finally, the treatment related-procedure codes that referred to other diseases despite thyroid cancer were disregarded as they might have overestimated the results.

In conclusion, the increasing incidence of thyroid cancer in Brazil seems to be directly associated with the performance of diagnostic procedures, as well as an increase in treatment-related procedures. These data suggest that large resources are allocated for diagnosis and treatment of a potentially indolent condition, which could remain unnoticed throughout one's lifetime. Therefore, it is important that thyroid cancer care be reexamined with a cost-conscious view, providing the best outcome that matters to the patient, relative to the cost of delivering it, especially in developing countries where healthcare resources are scarce.

Ethics approval and consent to participate: the study was approved by the Ethics Committee on Research from Federal University of Sao Paulo (Unifesp) under the National Research Database (Plataforma Brasil). The committee's reference number (CAAE) is: 58914516.8 .0000 .5505 .

Availability of data and material: all data is available publicly at www.datasus. gov.br. The raw data on the statistical analysis is available from the corresponding author upon reasonable request.

Authors' contributions: Carolina Castro Porto Silva Janovsky designed the study, collected the data, conducted the statistical analysis and wrote the manuscript. Marcio Sommer Bittencourt contributed to the statistical analysis, contributed to the discussion and reviewed the manuscript. Maykon Anderson Pires de Novais contributed to the study design and reviewed the manuscript. Rui Monteiro de Barros Maciel contributed to the discus- 
sion and reviewed the manuscript. Rosa Paula de Mello Biscolla designed the study, contributed to the discussion and reviewed the manuscript. Paola Zucchi designed the study, contributed to the discussion and reviewed the manuscript. All authors read and approved the final version.

Acknowledgements: the authors would like to acknowledge the Department of Informatics of the Brazilian Unified Health System (DATASUS) for the availability of the material and technical support when needed.

Funding: none.

Disclosure: no potential conflict of interest relevant to this article was reported.

\section{REFERENCES}

1. Ezzat S, Sarti DA, Cain DR, Braunstein GD.Thyroid incidentalomas. Prevalence by palpation and ultrasonography. Arch Intern Med. 1994;154(16):1838-40.

2. Leenhardt $\mathrm{L}$, Bernier MO, Boin-Pineau $\mathrm{MH}$, Conte Devolx $\mathrm{B}$, Maréchaud R, Niccoli-Sire $P$, et al. Advances in diagnostic practices affect thyroid cancer incidence in France. Eur $\mathrm{J}$ Endocrinol. 2004;150(2):133-9.

3. Udelsman $R$, Zhang $Y$. The epidemic of thyroid cancer in the United States: the role of endocrinologists and ultrasounds. Thyroid. 2014;24(3):472-9.

4. Guth S, Theune U, Aberle J, Galach A, Bamberger CM. Very high prevalence of thyroid nodules detected by high frequency (13 $\mathrm{MHz})$ ultrasound examination. Eur J Clin Invest. 2009;39(8):699-706.

5. Wartofsky L. The thyroid nodule: evaluation, risk of malignancy, and management. in: thyroid cancer. 2nd ed. New York, NY: Springer NewYork; 2016. p. 257-75.

6. de Matos PS, Ferreira APC, Ward LS. Prevalence of papillary microcarcinoma of the thyroid in Brazilian autopsy and surgical series. Endocr Pathol. 2006;17(2):165-73.

7. Yamamoto $Y$, Maeda T, Izumi K, Otsuka H. Occult papillary carcinoma of the thyroid. A study of 408 autopsy cases. Cancer. 1990;65(5):1173-9.

8. Franssila KO, Rubén Harach $\mathrm{H}$. Occult papillary carcinoma of the thyroid in children and young adults: a systemic autopsy study in Finland. Cancer. 1986;58(3):715-9.

9. Ottino A, Pianzola HM, Castelletto RH. Occult papillary thyroid carcinoma at autopsy in La Plata, Argentina. Cancer. 1989;64(2):547-51.

10. Brasil. Instituto Nacional do Câncer (Inca). Estimativa da incidência de câncer no Brasil em 2018. Brasília, DF. Ministério da Saúde; 2018.

11. Ahn HS, Kim HJ, Welch G. Korea's Thyroid-Cancer "Epidemic" Screening and Overdiagnosis. N Engl J Med. 2014; 371(19):1765-7.

12. Veiga LH, Neta G, Aschebrook-Kilfoy B, Ron E, Devesa SS. Thyroid cancer incidence patterns in Sao Paulo, Brazil, and the U.S. SEER program, 1997-2008. Thyroid. 2013;23(6):748-57.

13. Davies L, Welch HG. Increasing incidence of thyroid cancer in the United States, 1973-2002. JAMA. 2006;295(18):2164-7.

14. Ito $Y$, Nikiforov $Y E$, Schlumberger $M$, Vigneri R. Increasing incidence of thyroid cancer: controversies explored. Nat Rev Endocrinol. 2013;9(3):178-84.

15. Ward L, Graf H. Câncer da tiroide: aumento na ocorrência da doença ou simplesmente na sua detecção? Arq Bras Endocrinol Metabol. 2009;52(9):1-2.
16. International Atomic Energy Agency (IAEA). Investigation of excess thyroid cancer incidence in Los Alamos County (DOE/ AL/75237--T1). United States. Available from: https://inis.iaea.org/ search/citationdownload.aspx.

17. Brito JP, AI Nofal A, Montori VM, Hay ID, Morris JC. The Impact of Subclinical Disease and Mechanism of Detection on the Rise in Thyroid Cancer Incidence: A Population-Based Study in Olmsted County, Minnesota During 1935 Through 2012. Thyroid. 2015;25(9):999-1007.

18. Welch HG, Black WC. Overdiagnosis in cancer. J Natl Cancer Inst. 2010;102(9):605-13.

19. Sprague BL, Warren Andersen S, Trentham-Dietz A. Thyroid cancer incidence and socioeconomic indicators of health care access. Cancer Causes Control. 2008;19(6):585-93.

20. Vaccarella S, Franceschi S, Bray F, Wild CP, Plummer M, Dal Maso L. Worldwide thyroid-cancer epidemic? the increasing impact of overdiagnosis. N Engl J Med. 2016;375(7):614-7.

21. Registro de Câncer de Base Populacional. Câncer em São Paulo (RCBP-SP) 2008-2012.

22. Ward LS. Epidemiologia do câncer da tiroide no Brasil: apontando direções na política de saúde do país. Arq Bras Endocrinol Metabol. 2005;49(4):474-6.

23. Coeli CM, Brito AS, Barbosa FS, Ribeiro MG, Sieiro APAV, Vaisman M. Incidência e mortalidade por câncer de tireoide no Brasil. Arq Bras Endocrinol Metabol. 2005;49(4):503-9.

24. Brasil. Estimativa da incidência de câncer no Brasil em 2012. Instituto Nacional do Câncer (Inca). Brasília. DF: Ministério da Saúde; 2012.

25. Cordioli MICV, Canalli MHBS, Coral MHC. Increase incidence of thyroid cancer in Florianopolis, Brazil: comparative study of diagnosed cases in 2000 and 2005. 2009;53(4):453-60.

26. Rosario PW, Ward LS, Carvalho GA, Graf H, Maciel RMB, Maciel $L M Z$, et al. Thyroid nodules and differentiated thyroid cancer: update on the Brazilian consensus. Arq Bras Endocrinol Metabol. 2013;57:240-64.

27. Sinha P, Sunder G, Bendale P, Mantri M, Dande A. Coding System for Classification of Diseases and Related Health Problems. In: Sinha P, Sunder G, Bendale P, Mantri M, Dande A. Electronic Health Record. Hoboken, NJ, USA: John Wiley \& Sons, Inc; 2012. p. 111-7.

28. Stata 13.0. Disponível em: https://www.stata.com.

29. Sugitani I, Fujimoto Y. Management of low-risk papillary thyroid carcinoma: Unique conventional policy in Japan and our efforts to improve the level of evidence. Surgery Today. Springer Japan. 2010;40(3):199-215.

30. Penna GC, Mendes HG. Thyroid nodule $<1 \mathrm{~cm}$ and low-risk papillary thyroid microcarcinoma: what are today's management options? Endocrinol Metab Int J. 2016;3(4):1-3.

31. Oda $H$, Miyauchi $A$, Ito $Y$, Sasai $H$, Masuoka $H$, Yabuta $T$, et al. Comparison of the costs of active surveillance and immediate surgery in the management of low-risk papillary microcarcinoma of the thyroid. Endocr J. 2017;64(1):59-64.

32. Tan GH. Thyroid incidentalomas: management approaches to nonpalpable nodules discovered incidentally on thyroid imaging. Ann Intern Med. 1997;126(3):226-31.

33. Guth S, Theune U, Aberle J, Galach A, Bamberger CM. Very high prevalence of thyroid nodules detected by high frequency (13 $\mathrm{MHz})$ ultrasound examination. Eur J Clin Invest. 2009;39(8):699-706.

34. Perros P, Boelaert K, Colley S, Evans C, Evans RM, Gerrard Ba G, et al.; British Thyroid Association. Guidelines for the management of thyroid cancer. Clin Endocrinol (Oxf). 2014 Jul;81 Suppl 1:1-122.

35. Jin J. The US Preventive Services Task Force. JAMA. 2016;315(16):1804.

36. Park S, Oh CM, Cho H, Lee JY, Jung KW, Jun JK, et al. Association between screening and the thyroid cancer "epidemic" in South Korea: evidence from a nationwide study. BMJ. 2016;355:i5745. 
37. Tan GH, Gharib $H$. Thyroid incidentalomas: management approaches to nonpalpable nodules discovered incidentally on thyroid imaging. Ann Intern Med. 1997;126(3):226-31.

38. Ukrainski MB, Pribitkin EA, Miller JL. Increasing incidence of thyroid nodules and thyroid cancer: does increased detection of a subclinical reservoir justify the associated anxiety and treatment? Clin Ther. 2016;38(4):976-85.

39. ItoY, Miyauchi A, Inoue H, Fukushima M, Kihara M, HigashiyamaT, et al. An observational trial for papillary thyroid microcarcinoma in Japanese patients. World J Surg. 2010;34(1):28-35.

40. Ito $Y$, Miyauchi A. Is surgery necessary for papillary thyroid microcarcinomas? Nat Rev Endocrinol. 2011;8(1):1-1.

41. Haugen BR. 2015 American Thyroid Association Management Guidelines for Adult Patients with Thyroid Nodules and Differentiated Thyroid Cancer: What is new and what has changed? Cancer. 2016;123(3):372-81.

42. Roman BR, Feingold JH, Patel SG, Shaha AR, Shah JP, Tuttle RM, et al. The 2009 American Thyroid Association Guidelines modestly reduced radioactive iodine use for thyroid cancers less than $1 \mathrm{~cm}$. Thyroid. 2014;24(10):1549-50.

43. Cabana MD, Rand CS, Powe NR, Wu AW, Wilson MH, Abboud PAC, et al. Why don't physicians follow clinical practice guidelines? JAMA. 1999;282:1458-65.

44. Schlumberger M, Catargi B, Borget I, Deandreis D, Zerdoud S, Bridji B, et al. Strategies of radioiodine ablation in patients with low-risk thyroid cancer. N Engl J Med. 2012;366(18):1663-73.
45. Yamazaki CA, Padovani RP, Biscolla RPM, Ikejiri ES, Marchetti RR, Castiglioni MLV, et al. Lithium as an adjuvant in the postoperative ablation of remnant tissue in low-risk thyroid carcinoma. Thyroid. 2012;22(10):1002-6.

46. Janovsky CCPS, Maciel RMB, Camacho CP, Padovani RP, Nakabashi CC, Yang JH, et al. A prospective study showing an excellent response of patients with low-risk differentiated thyroid cancer who did not undergo radioiodine remnant ablation after total thyroidectomy. EurThyroid J. 2016;5(1):44-9.

47. Durante C, Montesano T, Attard M, Torlontano M, Monzani F, Costante $\mathrm{G}$, et al. Long-term surveillance of papillary thyroid cancer patients who do not undergo postoperative radioiodine remnant ablation: is there a role for serum thyroglobulin measurement? J Clin Endocrinol Metab. 2012;97(8):2748-53.

48. Durante C, Attard M, Torlontano M, Ronga G, Monzani F, Costante $G$, et al. Identification and optimal postsurgical follow-up of patients with very low-risk papillary thyroid microcarcinomas. J Clin Endocrinol Metab. 2010;95(11):4882-8.

49. Lamartina L, Durante C, Filetti S, Cooper DS. Low-risk differentiated thyroid cancer and radioiodine remnant ablation: a systematic review of the literature. J Clin Endocrinol Metab. 2015;100(5):1748-61.

50. James BC, Aschebrook-Kilfoy B, Cipriani N, Kaplan EL, Angelos $\mathrm{P}$, Grogan $\mathrm{RH}$. The Incidence and survival of rare cancers of the thyroid, parathyroid, adrenal, and pancreas. Ann Surg Oncol. $2016 ; 23(2): 424-33$. 